\title{
Caminhos e desafios da articulação de projetos de extensão orientados pela Educação Popular: reflexões com base em experiência na Universidade Federal da Paraíba
}

\author{
Aline da Silva Alves', Marcilane da Silva Santos², Pedro José Santos Carneiro Cruz ${ }^{3}$
}

\begin{abstract}
Resumo
O presente estudo pretende situar caminhos e desafios do processo histórico do Programa de Educação Popular em Saúde (PROGEPS) da Universidade Federal da Paraíba, enfatizando estratégias, metodologias, ações da articulação em rede de quatro projetos de extensão. Caracteriza-se como uma pesquisa qualitativa com coleta de dados por meio de fontes documentais. A presente pesquisa inferiu que a aproximação entre experiências extensionistas em educação popular pode fortalecer as possibilidades de criação de espaços institucionais de cunho crítico, proativo e participativo. Podem-se difundir, nas ações acadêmicas, metodologias orientadas para o desenvolvimento e aperfeiçoamento de trabalhos sociais, de estudos e de processos de formação voltados ao enfrentamento dos problemas sociais de grupos em situação de vulnerabilidade e exclusão. Assim, a dimensão do fazer dos projetos extrapola a prática comunitária e é capaz de propor alterações nos modos de pensar o fazer acadêmico como um todo. Um fazer voltado para a emancipação de sujeitos.
\end{abstract}

\section{Palavras-chave}

Extensão Universitária. Educação Popular. Redes. Articulação.

1. Especialista em Saúde da Família pelo Instituto de Medicina Integral Professor Fernando Figueira, Pernambuco, Brasil; residente em Saúde Mental pela Residência Multiprofissional em Saúde Mental da Universidade Federal da Paraíba, Brasil. E-mail: alinealves280@yahoo.com.br.

2. Mestranda em Educação (Educação Popular) na Universidade Federal da Paraíba, Brasil; pesquisadora do Grupo de Pesquisa em Extensão Popular (EXTELAR). E-mail: marcilane.santos@gmail.com.

3. Doutor em Educação (Educação Popular) pela Universidade Federal da Paraíba, Brasil; professor adjunto do Centro de Ciências Médicas e do Centro de Educação; líder do Grupo de Pesquisa em Extensão Popular (EXTELAR) na mesma instituição. E-mail: pjcruzpb@gmail.com. 


\title{
Paths and challenges of the articulation of extension projects guided by Popular Education: reflections based on experience at the Federal University of Paraíba, State of Paraíba, Brazil
}

\author{
Aline da Silva Alves ${ }^{*}$, Marcilane da Silva Santos $^{* *}$, Pedro José Santos Carneiro Cruz ${ }^{* * *}$
}

\begin{abstract}
The present study intends to locate paths and challenges of the historical process of the Program of Popular Education in Health (PROGEPS) of the Federal University of Paraíba, State of Paraíba, Brazil, emphasizing strategies, methodologies, and actions of the network articulation of four extension projects. It is characterized as a qualitative research with data collection through documentary sources. The present study inferred that the approximation between extensionist experiences in Popular Education can strengthen the possibilities of creation of institutional spaces with a critical, proactive and participatory nature. Methodologies aimed at developing and improving social work, studies and training processes aimed at coping with the social problems of groups in situations of vulnerability and exclusion can be disseminated in academic actions. Thus, the dimension of the projects' extrapolation goes beyond community practice and is capable of proposing changes in the ways of thinking the academic activity as a whole. An action towards the emancipation of subjects.
\end{abstract}

\section{Keywords}

University Extension. Popular Education. Networking. Articulation.

\footnotetext{
* Specialist in Family Health at the Integral Medicine Institute Professor Fernando Figueira, State of Pernambuco, Brazil; residency in Mental Health by the Multiprofessional Residency in Mental Health, Federal University of Paraíba, State of Paraíba, Brazil. E-mail: alinealves280@yahoo.com.br.

* Master degree student in Education (Popular Education), Federal University of Paraíba, State of Paraíba, Brazil; researcher of the Research Group on Popular Extension (EXTELAR). E-mail: marcilane.santos@gmail.com.

** PhD in Education (Popular Education), Federal University of Paraíba, Brazil; assistant professor of the Center of Medical Sciences and the Center of Education in the same institution; leader of the Popular Extension Research Group (EXTELAR). E-mail: pjcruzpb@gmail.com
} 


\section{Introdução}

Desde a década de 1950, a Educação Popular (EP) vem orientando práticas, movimentos e experiências no Brasil e na América Latina. Seu desenvolvimento se deu principalmente por meio de movimentos de educação e cultura popular, tais como: Movimento de Cultura Popular (MCP), Movimento de Educação de Base (MEB), Centro Popular de Cultura (CPC), Campanha de Educação Popular da Paraíba (CEPLAR), Experiência de Alfabetização de Adultos pelo Sistema Paulo Freire, em Angicos, no Rio Grande do Norte, dentre outras (FÁVERO, 2013). Tais experiências valorizavam a cultura no processo educativo e a construção de uma educação libertadora, uma cultura "verdadeiramente popular" (BRANDÃO, 2014, p. 6).

Com a inserção de profissionais de saúde nesses espaços, ao final da década de 1980, começou-se a incorporar os princípios da EP no setor saúde (VASCONCELOS; VASCONCELOS; SILVA, 2015), com o objetivo de promover um cuidado em saúde de forma mais humanizada, integral e horizontalizada. Assim, a EP passa a ser utilizada como instrumento de construção de uma atenção integral à saúde, articulando sujeitos e movimentos das classes populares, inicialmenteatravésda RededeEducação Popular e Saúde (REDEPOP) e da Articulação Nacional de Movimentos e Práticas de Educação Popular e Saúde (ANEPS) (MARANHÃO et al., 2014).

Ao longo dos anos, vários projetos de extensão universitária foram elaborados em diversas Universidades do Brasil tendo por base a EP, denominada extensão popular (CRUZ, 2017, p. 20). Dentre elas, a Universidade Federal da Paraíba (UFPB), que tem se destacado por suas experiências no campo da educação popular em saúde. Cabe destacar que o conceito de extensão universitária foi desenvolvido em 1987 e é definido como um "processo educativo, cultural e científico que articula o ensino e a pesquisa de forma indissociável e viabiliza a relação transformadora entre Universidade e Sociedade" (FORPROEX, 2007, p. 17).

Nesse sentido, a extensão popular não apenas se articula com o ensino e a pesquisa, ela preza pelo diálogo entre os sujeitos, está baseada nos saberes populares e é orientada por anseios emancipatórios de liberdade, justiça, igualdade e felicidade. Realizase por meio de estratégias como rodas de conversa, ações educativas, grupos focais, visitas domiciliares, participação em reuniões e mobilizações, numa vivência contínua de extensionistas com a comunidade (CRUZ, 2017), ultrapassando os muros da Universidade.

No que tange ao processo histórico dessas articulações extensionistas na Paraíba, mais especificamente na UFPB, um dos projetos pioneiros, no campo da extensão popular foi o Núcleo de Atuação Comunitária (NAC), criado no final da década de 1980, que aglutinava cerca de quarenta estudantes em atuação em uma pequena comunidade da periferia de João Pessoa, Paraíba (VASCONCELOS, 2011).

Essa imersão de professores e estudantes nas comunidades, por meio da extensão popular, foi expandida para outros espaços comunitários. Uma experiência marcante que vem se destacando na UFPB, por possibilitar que inúmeros estudantes dos diversos cursos adentrem em comunidades e mergulhem intensamente na realidade do cotidiano de pessoas que residem em comunidades, é o Estágio Nacional de Extensão em Comunidades (ENEC) que vem sendo desenvolvido desde 1987 por meio do Programa Interdisciplinar de Ação Comunitária (PIAC).

Em 1997, o Projeto de Extensão Educação Popular e a Atenção à Saúde da Família (PEPASF), desenvolveu-se na comunidade 
Maria de Nazaré, localizada no Bairro Funcionários II, João Pessoa-PB, inicialmente formado apenas por estudantes de medicina e, que ao longo do tempo, foi recebendo estudantes de outros cursos (VASCONCELOS, 2011). O projeto ganhou dimensão nacional por conta da participação dos estudantes em movimentos nacionais, congressos, encontros, seminários, documentários, o que contribuiu para a divulgação de suas experiências. A partir de 2006, passou a receber estágios curriculares de curta duração para residentes de Saúde da Família de diversas instituições brasileiras (VASCONCELOS, 2011). É importante destacar que a experiência do PEPASF serviu de inspiração para a construção de outros projetos de extensão popular, além de ter compartilhado experiências com projetos que passaram a atuar na mesma comunidade (VASCONCELOS, 2011).

O Projeto Práticas Integrais da Promoção da Saúde e Nutrição na Atenção Básica em Saúde (PINAB) surgiu em 2007 a partir da iniciativa de estudantes de nutrição, ex-extensionistas do PEPASF, e de uma professora do Departamento de Nutrição da UFPB; passando a atuar no Bairro Cristo Redentor, nas Comunidades Jardim Itabaiana I e II, Pedra Branca e Boa Esperança, em João Pessoa-PB (ARAúJO et al., 2015).

O Programa de Educação Popular e Saúde do Trabalhador (PEPST), atualmente denominado Programa Mais Saúde na Comunidade, ligado ao Departamento de Fisioterapia da UFPB foi desenvolvido em 2008 e suas práticas eram voltadas para atenção à saúde do trabalhador, cujo campo de atuação era as comunidades Grotão e Maria de Nazaré, em João Pessoa-PB (LACERDA et al., 2015).

Em seguida, no ano de 2010, foi criado o projeto de extensão denominado PalhaSUS, a partir de um espaço de formação de palhaços cuidadores, objetivando a atuação de estudantes de diversos cursos em instituições como Hospitais, Complexo Psiquiátrico e Instituições de Longa Permanência para
Idosos (ILPI) (COSTEIRA et al., 2013). A partir de 2012, os projetos de extensão popular supracitados se articularam em rede e originaram o Programa de Educação Popular em Saúde (PROGEPS) com a proposta de fortalecer e articular diversas lutas sociais envolvendo espaços, atores e militantes dos locais de atuação comunitária, bem como estudantes e professores de projetos de extensão popular.

Dessemodo, oestudoqueaquiseapresenta visa situar o processo histórico do PROGEPS, enfatizando estratégias, metodologias e ações da articulação em rede dos quatro projetos de extensão citados. Com base em tal experiência, espera-se evidenciar contribuições acerca dos caminhos e dos desafios da articulação em redes entre projetos de extensão, particularmente daqueles orientados pela perspectiva da EP.

\section{Metodologia}

O presente estudo caracteriza-se como uma pesquisa qualitativa do tipo documental, tendo como unidade de análise a experiência do PROGEPS/UFPB formado por quatro projetos de extensão popular da UFPB, a saber: PEPASF, PINAB, PEPST e PalhaSUS.

Na acepção de Fonseca (2002, p. 32), a pesquisa documental

trilha os mesmos caminhos da pesquisa bibliográfica, não sendo fácil por vezes distingui-las. A pesquisa bibliográfica utiliza fontes constituídas por material já elaborado, constituído basicamente por livros e artigos científicos localizados em bibliotecas. A pesquisa documental recorre a fontes mais diversificadas e dispersas, sem tratamento analítico, tais como: tabelas estatísticas, jornais, revistas, relatórios, documentos oficiais, cartas, filmes, fotografias, pinturas, tapeçarias, relatórios de empresas, vídeos de programas de televisão etc.

Para a coleta de dados foram utilizados registros visuais e escritos, considerando fontes 
documentais, a saber: propostas de projetos e programas ${ }^{4}$, articulados ao PROGEPS, que foram aprovadas em editais do Programa para Financiamento de Projetos de Extensão (PROEXT), do Ministério da Educação, compreendendo o período de 2012 a 2013, conforme disponíveis na plataforma SIGPROJ; relatórios dos citados projetos e programas no contexto do Programa de Extensão Universitária (PROEXT) no período de 2012 a 2013, conforme disponíveis na plataforma SIGPROJ; atas de reuniões ordinárias, de oficinas de planejamento e de oficinas de avaliação do PROGEPS, conforme disponibilizadas em acervo on-line do Programa (arquivadas no Google Drive). Segundo Cerllad (2008 apud SÁSILVA; ALMEIDA; GUINDANI, 2009, p. 2): "a análise documental favorece a observação do processo de maturação ou de evolução de indivíduos, grupos, conceitos, conhecimentos, comportamentos, mentalidades, práticas, entre outros". Desse modo, após levantamento dos registros, foi realizada análise documental com o objetivo de identificar e discutir as categorias (construção histórica, estratégias, metodologias e ações) previamente descritas no sentido de agrupá-las, perfazendo as seguintes etapas: a) Leitura e releitura dos documentos; b) Agregação à categoria de maior aproximação; c) Construção do diálogo com os diversos registros escritos e com as impressões dos pesquisadores a partir de suas experiências no Programa.

O tratamento e a análise desses documentos foram feitos a partir da perspectiva dialética que compreende a realidade em sua totalidade, como um processo histórico sabendo que ela está em constante movimento/ mudança, entendendo os sujeitos como objetos de conhecimento e transformação (HOLLIDAY, 2006, p. 8).

Vale salientar que esta pesquisa é fruto do Trabalho de Conclusão de Curso de Nutrição de uma das autoras, denominado “Educação popular em saúde para além da experiência local: alcances e limites da participação em rede de projetos de extensão", e tem profundo envolvimento com a realidade, vivência, experiência e participação da própria pesquisadora, que integrou o PROGEPS de 2012 a 2014, enquanto era extensionista do projeto PINAB e posteriormente do Projeto PalhaSUS.

\section{Resultados}

\section{O processo de construção do PROGEPS}

O PROGEPS nasceu do desejo e da necessidade de construir uma articulação mais organizada institucionalmente entre diferentes projetos de extensão popular da UFPB, que possibilitasse o compartilhamento de experiências e a implementação de ações mais estruturadas nas comunidades, objetivando ainda avançar na discussão dos caminhos de uma formação universitária mais participativa e engajada na realidade social. Desse modo, em 2012 iniciaram-se os primeiros passos para a construção desse programa, com o apoio do PROEXT, que a partir daquele ano começou a implementar e divulgar editais para financiamento de projetos de extensão universitária que consistia na concessão de bolsas para extensionistas e de materiais para a realização das ações dos projetos (câmeras, computadores, datashows, colchonetes), além

4. Sendo eles: "Formação em Educação Popular e Saúde" (coordenado pela professora Kátia Suely Queiroz Silva Ribeiro no âmbito do Departamento de Fisioterapia do Centro de Ciências da Saúde da UFPB no PROEXT do exercício 2012); "Práticas integrais de educação popular e saúde para promoção da organização popular e da segurança alimentar e nutricional" (coordenado pelo professor Rodrigo Toledo Pinheiro Vianna no âmbito do Departamento de Nutrição do Centro de Ciências da Saúde da UFPB no PROEXT do exercício 2012); e o “Programa de Educação Popular e Saúde" (coordenado pela professora Maria do Socorro Trindade Morais no âmbito do Departamento de Promoção da Saúde do Centro de Ciências Médicas da UFPB no PROEXT do exercício 2013). 
da sistematização de experiências e publicação de livros. Assim, aqueles projetos selecionados nos editais PROEXT conseguiam um suporte maior para a realização e divulgação das atividades, já que na Universidade eram escassos os recursos para divulgação dos projetos de extensão e para permanência de estudantes nos espaços de atuação, e inclusive em seus cursos de graduação, haja vista que a maioria deles necessitava de assistência estudantil para permanência na Universidade.

Em 2012, após algumas reuniões de planejamento, iniciaram-se as atividades do PROGEPS na UFPB. Um dos primeiros passos de cunho organizativo foi dividir o grupo em algumas comissões de trabalho, construídas ao longo do tempo, de acordo com as necessidades observadas em grupo: Comissão de Sistematização; Comissão de Formação; Comissão de Vivências; e Comissão do Fórum de Educação Popular em Saúde, as quais serão descritas aqui.

A Comissão de Sistematização surgiu com o objetivo de incentivar e promover a produção científica, por meio da escrita de resumos, relatos de experiências, artigos, documentários, que sistematizassem as experiências tanto específicas de cada projeto integrante como as compartilhadas pelo PROGEPS, enfatizando apresentações de trabalhos em congressos, seminários, colóquios, valorizando o espaço de construção compartilhada e a constante reflexão da realidade vivenciada em cada espaço comunitário.

A Comissão de Formação propunha criar espaços de aprofundamento teórico em assuntos relevantes em diálogo com a EP em saúde, por meio de reuniões teóricas, oficinas e cursos, visto que se reconhecia a necessidade de aprofundar o estudo sobre temáticas que emergiam dos espaços de atuação de cada projeto, bem como da articulação entre eles, prezando pelo estudo crítico e conhecimento da realidade social e dos modos de fazer inerentes à EP.
A Comissão de Vivências tinha por objetivo proporcionar aos participantes do PROGEPS momentos de integração em ambientes acadêmicos e extra-acadêmicos, além de momentos de cuidado e partilha. Assim, proporcionava-se o cuidado com o grupo, com as relações interpessoais e com as subjetividades de cada membro do programa.

A Comissão do Fórum de Educação Popular em Saúde propunha refletir, organizar e colocar em prática os encontros do Fórum Permanente de Educação Popular em Saúde, a saber: articulação com convidados/facilitadores das temáticas escolhidas pelo público participante (que eram os moradores das comunidades), espaço onde ele aconteceria, sua divulgação e operacionalização. Os Fóruns suscitavam, em discussões pertinentes sobre a realidade local de cada comunidade, a conjuntura política vivenciada à época, os desafios e enfrentamentos vivenciados nas comunidades e dilemas pelos quais os moradores - e a própria extensão universitária - passavam.

Assim, a cada encontro do grupo, acontecia a comunicação entre projetos, comissões e estudantes que se mobilizavam em torno dos encaminhamentos de cada comissão e, juntos, organizavam as ações para aquele período (bimestre ou trimestre). E, ao longo dos anos, tais comissões foram se aprimorando, sempre autogestadas por estudantes e professores, em articulação também com as comunidades.

\section{O PROGEPS em ação}

Oobjetivo primordial doPROGEPSsempre foi a articulação direta no e com o ambiente comunitário, prezando pela emancipação de seus atores sociais e colaborando para o fortalecimento de suas lutas. Nesse sentido, o programa começou a estruturar atividades que aconteciam localmente, na cidade de João Pessoa-PB, em comunidades acompanhadas pelos projetos de extensão popular. 
Assim, as frentes de atuação surgiram a partir das necessidades locais, explicitadas e avaliadas durante as reuniões organizativas do programa, que aconteciam na UFPB quinzenalmente, sendo elencadas: Fórum Permanente de Educação Popular em Saúde da Paraíba, oficinas de cenopoesias, vivências integrativas, cursos comunitários de saúde, reuniões organizativas e oficinas de planejamento e avaliação. Nesse sentido, cabe aqui uma breve explanação acerca das frentes de atuação acima mencionadas.

O Fórum Permanente de Educação Popular em Saúde da Paraíba, anteriormente descrita como Comissão, era também e principalmente uma das frentes de atuação do PROGEPS. O Fórum acontecia bimestralmente ou trimestralmente nas comunidades locais acompanhadas pelos projetos de extensão, sendo um espaço político de articulação com a sociedade em seus vários níveis. Nesses Fóruns, eram discutidas temáticas como: educação popular e espiritualidade; o papel da educação popular na atuação dos profissionais na estratégia de saúde da família; a política nacional de educação popular em saúde; análise da conjuntura da educação popular e saúde; práticas de educação popular em saúde: dificuldades e caminhos encontrados em nosso dia-a-dia, dentre outros. Desses Fóruns eram retirados principalmente encaminhamentos importantes referentes a cada temática no intuito de entender e melhorar a realidade local, bem como aprofundar discussões e ações políticas em um âmbito mais abrangente: município, estado e país. As oficinas de cenopoesias tinham por objetivo, a valorização da cultura popular nos espaços de construção compartilhada de conhecimentos. A primeira delas aconteceu em abril de 2012, na comunidade Maria de Nazaré, denominada "Cenopoesia e extensão popular: vivência em João Pessoa-PB", e a segunda realizada em outubro do mesmo ano, no Parque
Arruda Câmara, João Pessoa-PB, cujo tema foi "Cenopoesia e extensão popular: qual a nossa arte?", facilitadas por Ray Lima e Junio Santos, do Movimento Escambo de Teatro Livre de Rua.

As vivências integrativas entre os participantes dos projetos, como já mencionado anteriormente, tinham o sentido de gerar a integração entre estudantes e professores que faziam parte do PROGEPS e começaram a acontecer com maior frequência a partir de 2013, a exemplo: Vivência no assentamento Novo Salvador em Jacaraú-PB; Vivência na Aldeia Flor d'água, localizada na cidade do Conde-PB; e a Festa de São João realizada anualmente entre alunos e professores. Os cursos comunitários de saúde propunham contribuir com a formação de atores dos espaços comunitários (moradores, trabalhadores da saúde) e extensionistas, em temáticas que envolviam a EP e compreenderam o período de 2012 e 2013. Em 2012, foi realizado na comunidade Maria de Nazaré, o primeiro curso intitulado homonimamente "Curso Comunitário de Saúde"; e em 2013, realizado na UFPB, com a temática: "Caminhos metodológicos para sistematização em educação popular", ministrado pelo professor Pedro Cruz, além da parceria no curso "Atenção à saúde dos pobres, oprimidos e marginalizados", ministrado pelo Prof. Eymard Vasconcelos, realizado na UFPB, tendo como público-alvo trabalhadores da área de saúde e extensionistas.

As reuniões organizativas, realizadas no âmbito da UFPB, também faziam parte das ações do PROGEPS, porém abrangiam um âmbito mais interno do programa, cujos participantes eram os estudantes e professores. O objetivo primordial era o de planejar as ações e discutir com o coletivo.

As oficinas de planejamento e avaliação eram realizadas anualmente, com o intuito de construir um calendário de atividades a cada ano, com o enfoque práxico (reflexão-ação-reflexão). Assim, no decorrer do seu desenvolvimento, 
o PROGEPS passou por várias mudanças, a partir da constante reflexão de suas práticas.

Em 2012 as ações do Programa se desenvolviam muito timidamente, por meio dos encontros do Fórum Permanente de Educação Popular em Saúde, de reuniões de formação integradas entre os diferentes projetos e das oficinas de cenopoesias ou do curso comunitário de saúde. Contudo, no ano de 2013, com a submissão e aprovação no edital do PROEXT, o programa se estruturou e passou a construir ações por meio de um Colegiado Gestor.

O Colegiado surgiu como uma estratégia potente de aglutinar extensionistas para a conjuntura administrativa do programa fortalecendo-o juntamente com os professores coordenadores. Assim, formou-se um coletivo de estudantes representantes de cada projeto que assumiram o compromisso de articulação entre os projetos, organizando as reuniões e resolvendo demandas administrativas do PROGEPS. Assim, nas diversas atividades estavam presentes elementos como o diálogo, a interdisciplinaridade, a troca de experiências entre grupos e pessoas, o incentivo para a escrita científica, a construção da visão crítica dos estudantes e o protagonismo estudantil. A cada encontro se fazia presente a potencialidade do trabalho em rede, por enfatizar a riqueza que há na execução de atividades coletivas, um fazer entremeado por vivências que partiam da realidade local de cada projeto, cada um com modos de fazer bastante específicos (apesar de possuírem formatos semelhantes), pois partiam das necessidades de cada território de atuação.

Neste período foram também observadas dificuldades em alguns momentos históricos do PROGEPS, como por exemplo, a falta de aprofundamento político em debates internos e com a comunidade, principalmente por questões de cunho organizativo, tendo em vista que os estudantes se desdobravam em várias atividades acadêmicas e, por vezes, Ihes faltava tempo hábil para essa discussão mais estruturada dentro e fora do âmbito acadêmico. Além disso, em alguns momentos do programa, os espaços de cuidado estiveram frágeis, pelo mesmo motivo anteriormente citado. Tal ausência foi percebida e mencionada por alguns extensionistas durante as reuniões do programa, em que se discutiu sobre a necessidade de retomá-las para proporcionar um melhor relacionamento interpessoal e a redução de tensões e estresses causados pelas atividades acadêmicas. Vale ressaltar que as ações do PROGEPS contribuíram para o fortalecimento da educação popular e da extensão popular dentro da UFPB - caso da implementação, em 2012, da Coordenação de Educação Popular (COEP), ligada à Pró-reitoria de Assuntos Comunitários (PRAC) -, e no estado da Paraíba - pioneiro na construção, em 2014, de um Núcleo de Educação Popular em Saúde (NEPOPS-PB).

O PROGEPS galgou sonhos, realizou objetivos e contribuiu para a formação e construção de uma sociedade mais empoderada, politizada, proporcionando uma visão crítica da sociedade. Contribuiu, ainda, para a formação de profissionais mais sensibilizados com as causas sociais e articulados em um âmbito mais expansivo, suscitando nos extensionistas a reflexão do fazer em educação popular para além da prática comunitária.

Desta feita, no que tange ao fazer metodológico, o PROGEPS alcançou uma estrutura de articulação que pode ser replicada em experiências semelhantes que busquem uma articulação em rede, principalmente aquelas embasadas na EP.

A articulação em rede no campo da extensão em educação popular vem trazendo importantes frutos, contudo o mais significativo é a possibilidade do desenvolvimento da troca de conhecimentos e do consequente fortalecimento das práticas pelo aprendizado com os caminhos de construção de outros projetos e ações extensionistas. Como destacado por Cruz e Marcos (2013, p. 297): 
a articulação se configura como uma rede, não apenas de pessoas, mas de sentimentos, utopias, metodologias, experiências, críticas, teorias e tendências. As redes articuladoras da educação popular cumprem uma importante função - a de trazer à tona a diversidade própria e característica da educação popular. Em diferentes experiências, essa vertente educativa propiciará distintas repercussões, por meio de variados jeitos de fazer, com diferentes inspirações. Em cada cenário sóciopolítico-geográfico, também se revelará rica a prática da educação popular. Por tudo isso, sempre se valorizou a troca de experiências propiciada pelas articulações de educação popular, através das quais vão se delineando críticas às experiências, partilhando-se os esforços do cotidiano e se afirmando algumas certezas já verificadas no seio das experiências.

\section{Alguns desafios da construção do PROGEPS}

No que tange aos desafios para constituição do PROGEPS como uma potente articulação em rede para os projetos envolvidos, apresentaram-se alguns elementos no desenvolvimento de suas atividades.

Uma dificuldade foi a de integrar diferentes sujeitos que, apesar de serem norteados pela educação popular, apresentam diferentes formas de agir, de colocá-la em prática. Além disso, trazer esses sujeitos - centrados em suas práticas específicas locais em seus respectivos projetos - para a construção e o desenvolvimento de um espaço em comum, trouxe demandas em sensibilizar esses sujeitos a adentrarem nessa perspectiva ampliada, coletiva e relacional.

Outra questão foi a ausência de alguns dos professores coordenadores dos projetos em algumas reuniões, o que constituiu um desafio para o andamento do programa, já que muitos encaminhamentos precisariam ser discutidos com eles, visto que, institucionalmente, os estudantes sozinhos não conseguem resolver uma série de questões acadêmicas. Assim, o
PROGEPS foi predominantemente liderado pelos estudantes. Contudo, tal realidade se aplicava principalmente aos estudantes bolsistas e havia dificuldade frequente em envolver os estudantes voluntários para participarem das ações do PROGEPS. Nesse sentido, a excessiva carga horária de cursos de saúde e sua organização curricular sempre inquietaram os estudantes e provocaram inúmeras discussões. Essa carga horária é composta de forma maciça por aulas, deixando poucos espaços para pesquisa e/ou extensão. Ademais, há ainda uma percepção da extensão como atividade pouco valorizada diante da pesquisa e das atividades ligadas ao ensino (a exemplo, a monitoria).

Nessa direção, para os projetos se articularem em rede, os componentes do PROGEPS apontaram como desafios: a necessidade de seus sujeitos problematizarem essa realidade acadêmica e refletirem sobre caminhos pelos quais o espaço da extensão pudesseserfortalecido no conjunto doscurrículos universitários, e a valorização da participação em seus projetos diante daqueles no âmbito do ensino e da pesquisa. Muitas vezes, é preciso que os sujeitos dos projetos de extensão sigam para além dos espaços em que esses projetos atuam, não se limitando, portanto, à consecução de ações sociais, técnicas e/ou comunitárias, mas permitindo-se discutir e propor melhoramentos na estrutura curricular e universitária. É preciso repensar a forma de organização dos projetos de extensão em educação popular, no sentido de que haja espaços para que suas ações repercutam em um protagonismo de seus sujeitos no contexto do aprimoramento da indissociabilidade entre extensão, pesquisa e ensino.

No caso do PROGEPS, foi possível perceber estudantes e docentes que, se sentindo provocados pela atual conjuntura acadêmica, partiram para ocupar crítica e criativamente outros espaços, como movimento estudantil, 
movimento docente, centros acadêmicos, espaços de gestão acadêmica, conselhos universitários, entre outros. Contudo, diante do número total de envolvidos nos projetos, ainda é pequena a proporção das pessoas que vão além da especificidade de suas ações extensionistas.

Uma questão que a articulação em rede ajuda a enfrentar é o localismo e o basismo de algumas das ações extensionistas, ou seja, a restrição do protagonismo docente, técnico e discente ao projeto no qual atua.

Outra dificuldade observada no PROGEPS diz respeito à aproximação dos sujeitos das comunidades às quais os projetos atuam, para participarem ativamente das ações do programa.

Finalmente, há que se ponderar que um desafio dominante na construção do PROGEPS consistiu na inconstância e na rotatividade da composição dos membros dos projetos de extensão, especialmente o público estudantil. Em virtude de saídas de componentes dos projetos, como diante de novas seleções de participantes, periodicamente se fazia necessária uma explanação do que era o programa, o que ele pretendia, entre outros elementos. Mesmo assim, somente na prática é que as pessoas realmente começam a entender as ações.

\section{Considerações finais}

A presente pesquisa inferiu que a articulação em rede de experiências extensionistas em educação popular pode fortalecer as possibilidades de criação de espaços institucionais de cunho crítico, proativo e participativo nas universidades. Nessa construção específica, esse fortalecimento aconteceu, em grande parte, pelo protagonismo dos estudantes extensionistas que contribuíram para que o espaço se tornasse grande potencializador do movimento estudantil, o que, em longo prazo pode contribuir com o compromisso e as lutas de outros segmentos da sociedade. A partir do PROGEPS alguns estudantes ampliaram seu olhar sobre a EP e os espaços nos quais ela está atualmente inserida, sendo fonte de inspiração e prática na militância da autonomia dos sujeitos.

A construção orgânica do PROGEPS no período estudado ocorreu de forma horizontal e dialógica, contribuindo para o fortalecimento de vínculos entre integrantes dos projetos de extensão que compunham o programa. Além disso, as práticas realizadas com as comunidades, os fóruns permanentes e demais espaços elencados no estudo, favoreceram a aproximação entre os saberes e a valorização das práticas construídas no campo popular.

No que tange à dimensão da articulação em rede, fica evidente que esse trabalho proporcionou aprendizados para os projetos, promovendo não apenas a interação entre extensionistasdediversasáreasdoconhecimento, mas também trazendo a importância de utilizarse desses espaços institucionais para enfatizar o debate político e o aspecto do cuidado humano.

Inúmeros desafios foram identificados e enfrentados ao longo do caminho, pois cada projeto possuía sua metodologia de trabalho específica, o que em determinados momentos provocava discordâncias e incoerências que eram problematizadas e discutidas também em grupo. Situações como a ausência de docentes coordenadores nas reuniões para a resolução de questões burocráticas, rotatividade de participantes e pouco envolvimento de voluntários foram apontadas neste estudo, o que nos faz refletir acerca da complexidade de uma construção em rede que só é possível com bastante diálogo, envolvimento, participação, confiança e respeito entre os pares. Os alcances e limites identificados no PROGEPS ajudam-nos a refletir que planejamento, diálogo e compromisso são os principais pontos para a construção de uma articulação em rede em espaços acadêmicos, principalmentese essa articulação estiver pautada nos princípios da EP, na medida em que tal perspectiva pedagógica conflui na emergência de 
abordagens que possibilitam o reconhecimento das subjetividades dos atores sociais, seus limites e sua condição de eternos aprendizes.

A constante práxis da articulação em rede por meio do PROGEPS contribuiu para reorientar práticas locais em cada projeto, bem como para a troca de experiências entre comunidades, fortalecendo, assim, uma rede articuladora externa à própria universidade. Experiências semelhantes, orientadas pela EP, são pertinentes em espaços institucionais e comunitários que busquem a realização de um trabalho coletivo voltado para as causas sociais e a emancipação de sujeitos. Assim, a extensão orientada pela Educação Popular, quando articulada em rede, pode contribuir para iniciativas e processos de construção de sujeitos propositivos, dialógicos, sensíveis e engajados na realidade social em que vivem, e assim, contribuir para a realização de transformações institucionais e sociais.

\section{Referências}

ARAÚJO, E. P. S. et al. Educação popular no processo de integração ensino-serviço e comunidade: reflexões com base em experiências na extensão. Rev. APS, Juiz de Fora, v. 18, n. 4, p. 448, outdez. 2015.

BRANDÃO, C. R. Paulo Freire: a educação, a cultura e a universidade: memória de uma história de cinquenta anos atrás. EJA em debate, Florianópolis, ano 3, n. 4, p. 6, jul. 2014.

COSTEIRA, A. A. M. F. et al. Projeto de extensão PalhaSUS: o palhaço cuidador desenvolvendo a prática da educação popular. In: Seminário Nacional de Pesquisa e Extensão Popular - SENAPOP, 1., 2013, João Pessoa. Anais... João Pessoa: UFPB, 2013. p. 385.

CRUZ, P. J. S. C. Extensão popular: situando a extensão universitária orientada pela educação popular. In: CRUZ, P. J. S. C. et al. (Org). Extensão popular: caminhos em construção. João PessoaPB: CCTA, 2017. p. 20-22.

CRUZ, P. J. S. C.; MARCOS, M. L. A Articulação Nacional de Extensão Popular (Anepop): os primeiros passos de um movimento para a construção de outra universidade possível. In: CRUZ, P. J. S. (Org.). Educação popular na universidade reflexões e vivências da Articulação Nacional de Extensão Popular (Anepop). São Paulo: Hucitec; João Pessoa: Editora Universitária UFPB, 2013. p. 273-298.

FÁVERO, O. Paulo Freire: primeiros tempos. Em Aberto, Brasília, v. 26, n. 90, p. 48-49. 2013.

FONSECA, J. J. S. Metodologia da pesquisa científica. 2002. Disponível em: <http://leg.ufpi. br/subsiteFiles/lapnex/arquivos/files/Apostila_-_METODOLOGIA_DA_PESQUISA\%281\%29.pdf> Acesso em: 22 maio 2018.

FORPROEX - Fórum de Pró-Reitores de Extensão das Universidades Públicas Brasileiras. Extensão Universitária: organização e sistematização. Belo Horizonte: Coopmed, 2007.

HOLLIDAY, O. Para sistematizar experiências. 2. ed. Brasília: MMA, 2006. p. 8.

LACERDA, D. A. L. et al. Educação popular e controle social em saúde do trabalhador: desafios 
com base em uma experiência. Interface: Comunicação, Saúde, Educação. v. 18, supl 2, p. 1.378, 2014.

MARANHÃO, T. M. et al. Espaços de saúde e cultura: experiência do Fórum Social Mundial às Tendas de Educação Popular em Saúde. Interface [online], Botucatu, v. 18, Supl. 2, p. 1.178, 2014. Doi: http://dx.doi.org/10.1590/1807-57622013.0472.

SÁ-SILVA, J. R.; ALMEIDA, C. D.; GUINDANI, J. F. Pesquisa documental: pistas teóricas e metodológicas. Revista Brasileira de História \& Ciências Sociais, São Leopoldo, v. 1, n. 1, p. 2, jul. 2009. Disponível em: <https://www.rbhcs.com/rbhcs/article/view/6/pdf>. Acesso em: 12 abr. 2018.

VASCONCELOS, E. M. Educação popular na universidade. In: VASCONCELOS, E. M; CRUZ, P. J. S. C. (Org.). Educação popular na formação universitária: reflexões com base em uma experiência. São Paulo: Hucitec; João Pessoa: Editora Universitária da UFPB, 2011. p. 21-238.

VASCONCELOS, E. M.; VASCONCELOS, M. O. D.; SILVA, M. O. A contribuição da educação popular para a reorientação das práticas e da política de saúde no Brasil. Revista da FAEEBA: Educação e Contemporaneidade, Salvador, v. 24, n. 43, p. 91, jan.-jun. 2015. Doi: http://dx.doi. org/10.21879/faeeba2358-0194.2015.v24.n43.p\%25p

Submetido em 2 de setembro de 2018.

Aprovado em 25 de setembro de 2018. 